\title{
ENHANCING THE EFFECTIVENESS OF INTERDISCIPLINARY MENTAL HEALTH TREATMENT TEAMS
}

\author{
Diane Vinokur-Kaplan, M.S.W., Ph.D.
}

\begin{abstract}
Mental health administrators often lack guidelines for promoting and evaluating the effectiveness of interdisciplinary clinical treatment teams. This article describes the use of a model of group effectiveness that elucidates several aspects of team effectiveness. Also discussed are how administrators can support such teams by reviewing their initial set-up, how the organization influences the team's productivity and longevity, and how team members can better understand one another's personal and professional frames of reference to improve mutual collaboration.
\end{abstract}

The interdisciplinary clinical treatment team in psychiatric hospitals and community mental health centers is recognized as the usual provider of holistic planning and treatment for mental health consumers, and a necessary forum for professional communication, coordination, and accountability (Bond et al., 1991; Ducanis \& Golin, 1979; Frazier, 1985). Yet, mental health administrators have few guidelines for facilitating the productivity of such groups that are based on well-developed models of team effectiveness. This situation is especially acute in the current times of major transitions in the delivery of mental health services, which engender increased hospital downsizings and closures, and the continuing development of community care for the mentally ill (Ramon, 1992; Vinokur-Kaplan \& Walker-Burt, 1994). This paper outlines such guidelines, applying an established model of work groups and team effectiveness to mental health teams. This article departs from previous litera-

Diane Vinokur-Kaplan is Assistant Professor at The University of Michigan School of Social Work, 1065 Frieze Building, Ann Arbor, MI 48109.

An earlier version of this paper was presented at the Annual Program Meeting of the Council on Social Work Education, New York, February 28, 1993. 
ture that emphasized the phases of team development (Bailey, 1991), or that focused primarily on interpersonal team dynamics and leadership (Yank, Barber, Hargrove, \& Whitt, 1992). Instead, this article highlights the organizational conditions that influence team effectiveness, conditions for which mental health administrators hold responsibility. and influence. Moreover, it specifically addresses the challenges inherent in the interdisciplinary collaboration required in such teams.

\section{DEFINITIONS OF TEAMS AND GROUP EFFECTIVENESS}

In their 1986 article about the role of social workers on teams in psychiatric hospitals, Toseland, Palmer-Ganeles, \& Chapman (1986) provide a helpful definition of a team: ". . . A number of individual staff members, each of whom possesses particular knowledge and skills, who come together to share their expertise with one another for a common purpose" (p. 46). More recent definitions have made even more explicit the interdependency of team members. For example, Salas (1993), an organizational psychologist, defines a team as "Two or more individuals who must interact interdependently and adaptively to achieve specified, shared and valued objectives" (p. 9). The emphasis on interdependence is helpful in that "it excludes groups in which members may interact (e.g., a problem-solving group), but are not required to coordinate activity in order to reach their goal" (p. 10). In addition, mental health treatment teams are often regarded as interdisciplinary teams, characterized by cooperation, coordination, and equality, and grounded in a higher-level concept, such as "the health and welfare of the client" (Shalinsky, 1989, pp. 205, 209). In such groups, each profession's contribution is equally appreciated and felt needed to best serve the overarching goal.

Thus, following Hackman $(1987,1990)$ and other organizational psychologists (Goodman, Ravlin, \& Argote, 1986; Sundstrom, DeMeuse, \& Futrell, 1990) who emphasize looking at teams within the ecology of an organization, treatment teams, like other teams, should be seen as:

\footnotetext{
real groups... intact social systems, complete with boundaries, interdependence among members, and differentiated members roles (Alderfer, 1977) . . (they) have one or more tasks to perform . . . some outcomes for which members have collective responsibility and whose acceptability is potentially assessable ... [and] they operate in an organizational context (Hackman \& Associates, 1990, p. 4).
}

\section{TEAM EFFECTIVENESS AND ITS PRECEDING CONDITIONS}

One of the major models now used to evaluate team productivity is Hackman's normative model of team effectiveness (1987). It was utilized in a demonstration project (Figure 1) to enhance the effectiveness of clinical treatment teams in public psychiatric hospitals (Vinokur-Kaplan, 1993). 


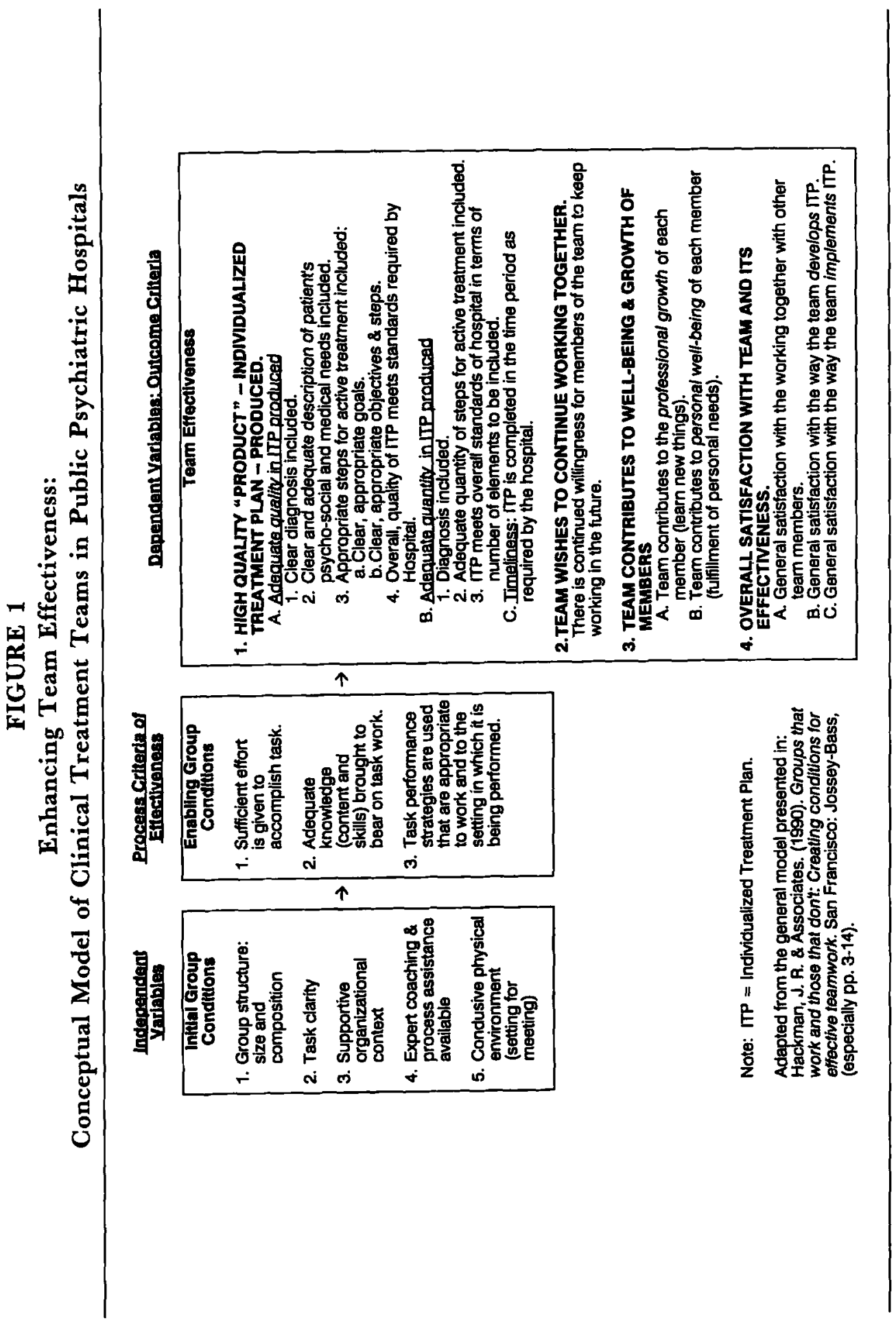


As shown, Hackman delineates three types of outcomes that should be included in measuring team effectiveness, plus the initial and enabling conditions that facilitate team effectiveness (Hackman, 1987; Hackman \& Associates, 1990). Thus, a team's effectiveness depends on its standing with regard to the three following dimensions (Hackman \& Associates, 1990).

1. The degree to which the group's productive output (that is, its product, service or decision), meets the standards of quantity, quality, and timeliness of the people who receive, review, and/or use that output (p. 4).

In the case of clinical treatment teams, it is a comprehensive, interdisciplinary, individualized treatment plan that meets the hospital's standards of quality, quantity, timeliness, implementation and, when applicable, standards of reimbursement agencies.

2. The degree to which the process of carrying out the work enhances the capability of members to work together interdependently in the future (p. 4).

This means that teams do not "burn themselves out" in producing their treatment plans or other products, possibly "winning the battle but losing the war"; members would want to continue to work with all the members in the future.

3. The degree to which the group experience contributes to the growth and personal wellbeing of its members (p. 5).

For hospital psychiatric teams, this could include each team member's identity as a mental health professional, the team's aiding the teammate to learn new areas and ideas, and the team's contributing to his/her personal sense of wellbeing.

\section{Initial Conditions}

In order for teams to be effective, the groups first benefit from being "set up right in the first place . . . [or having] initial conditions of group structure that promotes competent work on the task" (Hackman \& Associates, 1990, p. 10). These structural features include:

1. A task structure that is clear and consistent with a group's purpose and "high on what Hackman and Oldham (1980) call motivating potential ... [the team has] a meaningful piece of work to do for which members share responsibility and accountability and that provides opportunities for the team to learn how well it is doing" (Hackman \& Associates, 1990, p. 10). 
For clinical psychiatric treatment teams, the task structure includes an individualized treatment plan that ideally incorporates problems, goals and objectives that are positive, observable, and measurable for each patient's individualized treatment plan, and incorporates the contributions of all disciplines.

2. Group composition, namely a group has an appropriate size and mix of talents and interpersonal skills needed for communication and coordination with one another (Hackman \& Associates, 1990, p. 10).

For clinical psychiatric treatment teams, this includes all the requisite disciplines treating the patients. In some cases, para-professionals (Lichtenberg, Strzepek, \& Zeiss, 1990) and trainees (Stahelski \& Tsuduka, 1990) should be included. Teams in psychiatric hospitals often have at least five members, representing the disciplines of activity therapy, nursing, psychology, psychiatry, and social work. And at a VA hospital serving an elderly veteran population, Stahelski \& Tsuduka (1990) reported a range from 12 to 30 team members.

3. Core norms that regulate member behavior and promote coordination and "continuous scanning of the performance situation and pro-active planning of group performance strategies ..." (Hackman \& Associates, 1990, p. 11).

In hospitals and other interdisciplinary settings, it is especially necessary to clarify these norms, of individual or shared responsibility by discipline: "Who's in charge?" or "Is leadership shared?" In mental health systems that are in the process of closing hospitals and furthering community care, it would seem especially important to instill productive norms that promote team members' contributions, the adoption of innovation (Ramon, 1992), and constructive social support to forestall the pitfalls of both "burnout" (Leiter, 1988) and avoidance of "groupthink" (Janis, 1971), in which groups disregard critical information to maintain their cohesion. (For example, establishing the acceptable norm for any team member to play "devil's advocate" in team discussions can help prevent this problem.) Such clarification also keeps so-called interdisciplinary teams from actually functioning as cross-disciplinary, with one discipline dominating.

These initial conditions also include establishing an organizational context that helps set up the team for greater effectiveness. Such an environment includes providing a comfortable, confidential site to hold team meetings, equipped with accoutrements to aid the team's work (such as staff answering machines to avoid meeting interruptions, writing surfaces, dictating machines, 
portable computers, or audio-visual equipment). This context should support and reinforce team excellence through its systems of rewards, education, and information; it should have available expert coaching and consultation assistance regarding team members' effort, knowledge, and skills, and performance strategies for when teams "get stuck" or when unproductive conflict prevails (Hackman \& Associates, 1990, pp. 11-13). It should also reflect the importance it accords team's activities by maintaining the team's planned meetings and by not condoning unnecessary interruptions or scheduling competing obligations.

\section{Enabling Conditions}

Once set up, the team's effectiveness is also enabled by appropriate actions by team members that surmount three hurdles. A group must (1) exert sufficient effort to accomplish the task at an acceptable level of performance; (2) bring adequate knowledge and skill to bear on the task work; and (3) employ task performance strategies that are appropriate to the work and to the setting in which it is being performed (Hackman \& Associates, 1990, p. 9).

For clinical treatment teams, these actions include: (1) attending the team meeting (both in terms of being present throughout the meeting and focusing on and contributing to the meeting); (2) displaying appropriate interdisciplinary collaboration as required by the treatment plan and the hospital (Rendell, 1988); (3) conducting appropriate task performance strategies, which may include gathering information from absent members, such as paraprofessionals or professionals on other shifts; (4) implementing a clear delegation of tasks and a system to monitor completion of tasks; and (5) promulgating appropriate communication and clear roles and communication with other parts of the organization as needed (Ancona \& Caldwell, 1990).

\section{TEAM EFFECTIVENESS \& DISCIPLINARY DIVERSITY}

Hackman's model has been very helpful in conceptualizing team effectiveness in general. However, the interdisciplinary nature of mental health treatment teams requires that additional efforts be made regarding the setting up of teams and the efforts expended by members.

\section{Initial Conditions}

The size and composition of the group's structure automatically lead to the issue of inclusion. Which disciplines and professions are included, and which are not is obvious in its implications for comprehensive treatment planning. The question of inclusion of para-professionals or other professions (such as clergy) also arises. Furthermore, the presence of too many representatives from the same profession is unnecessary duplicative and can lead to an unwieldy group process.

The clarity of the task is often influenced by the disciplinary perspectives and paradigms to which each team member has been socialized. For example, to a 
team's social worker, the task of preparing the patient's treatment plan, might automatically bring to mind integration and involvement of the patient's significant others. For other team members, such a concern might not be salient. Without agreement among all members that the plan should provide for the "body, mind, and supportive environment" of the patient, important elements can be left out of the plan, and social work professionals might feel devalued. Thus, it is important for the team to review early on the norms that the members bring regarding content, process, and contributions, and also those that the organization communicates to its employees; and administrators should be sure that time is initially allocated to clarify these issues as part of the necessary team-building process.

If such clarification and mutual understanding is not done early on, it may be necessary to utilize expert coaching and process assistance to bring a team back to a more effective plane. This may include brief retreats where all members re-establish norms of interdependence, cooperation, and overall values. Alternatively, especially articulate professionals might be sent to help train and explain to members of other teams how their own team works effectively, as a cost-effective means to provide in-house training and consultation (Vinokur-Kaplan \& Walker-Burt, 1994).

Further influencing the team's effectiveness is the organizational context. If the organization's subsystems that provide rewards, information, and training reflect only one discipline, then true interdisciplinary activity is not being supported. This author recently saw a simple-but symbolic-example when recently visiting a psychiatric inpatient center at a large medical complex. On the wall were formal photographs and names of all the psychiatrists who work there - where were the other team members?

\section{Enabling Conditions}

Sufficient effort, knowledge and skill must be given to the particular task at hand; but in interdisciplinary work, adequate effort, knowledge, and skills must also be brought to render a mutual understanding and respect among disciplines. Several approaches have been put forward in the health and mental health areas during the last decade. For instance, Lister (1982) developed training modules to help health team members in Hawaii mutually clarify their professional roles and also deal with the impact of each member's gender and ethnocultural roles on their formal and informal roles as team members. Folkins, Wieselberg, \& Spendey (1981) exposed discipline stereotyping among psychiatrists, psychologists, and psychiatric social workers working in community mental health, using an adjective checklist.

Shalinsky (1989) has called for members of various disciplines on such teams to "undo paradigm blinders" (p. 212) and to promote "constructive polydisciplinary work" (p. 211) by applying approaches such as Delkeskamp (1977, pp. 342343 ) "that might lead to a critical revision of conceptual assumptions within each 
discipline" Shalinsky, p. 212). Firstly, members of each discipline expose themselves to others' common perceptions of their profession; they also expose their own disciplinary perspectives by applying the categories of their own field to the others' disciplines. Secondly, they seek to apply another discipline's concepts to their own profession and try to discover areas of applications. Thirdly, members reflect on how they now view and understand the other disciplines and the new insights gained from such applications. Ramon (1992) recently cited a similar bases of power exercise, originally developed by Barker (1989), in which each discipline's team representative presents their perception of their own discipline's power base, that of other professions, and how it may be used to enhance the power of service users. Such an exercise helps to challenge myths regarding the power of different disciplines and the powerlessness of service users. A team's willingness to engage in such reflective criticism is aided by the presence of positive feelings and trust among members. Such cohesion-building activities as formal team-building training and informal social celebrations, plus such organizational "props" as uniforms, team songs, mottoes, and humor may help maintain team cohesion.

Shalinsky (1989) further notes that for these disciplinary blinders to be undone, team members must be able to use a common language. This is not always easy. He cites Cassell (1977): "For any successful interdisciplinary work the jargon has to go. When it goes it is rather like pulling off a wart; it leaves bleeding" (Shalinsky, 1989, p. 214).

Furthermore, the media of transmission for each profession needs to be respected. Whereas some professionals tend to rely on words and numbers, others think and convey their thoughts more visually. For example, Ostrander (1974), writing on interdisciplinary communication between behavioral scientists and architects, quips to a designer colleague, "I won't laugh at your writing if you don't laugh at my drawings" (quoted in Shalinsky, 1989, p. 215).

Finally, Hackman's outcome criteria serve to caution mental health administrators to heed the long term implications of not investing in having disciplines understand one another. First, the quality, quantity, and timeliness of the team's mutually produced product or service is likely to suffer when the team members' needs and perspectives are not appreciated. Second, lack of enthusiasm for each disciplines' contribution can also undermine the cohesiveness of the group, bringing staff turnover and requiring even further reinvestment to enhance the group's process and norms. Finally, the well-being and growth of teammates, and their capacity to endure stress, is probably fostered by the group's mutual respect for their well-being and expertise, and the peer learning gleaned from team members' contributions of their respective perspectives.

\section{CONCLUSIONS}

Mental health administrators manage organizations that are populated by interdisciplinary teams responsible for planning and implementing the effec- 
tive treatment and care of mental health consumers. This paper offers a model of team effectiveness that emphasizes the administrators' roles in getting the clinical treatment teams "set up right" in the first place, and then supporting team members' efforts to do their work on an ongoing basis.

Each discipline's frame of reference should be shared and understood in order to facilitate their productivity in a synergistic fashion (Mitchell, 1986). Thus, administrators should review their team treatment plans for timeliness, quantity, and quality, all recognized and appropriate organizational objectives; but they should also consider ways the organization can reward teams for effective group performance, and support and enable them when assistance is needed-especially given the additional challenges posed by interdisciplinary collaboration. They should additionally consider how they can support the personal and group goals of team members, in order to help assure the long-term viability and productivity of the team, especially during times of transition.

\section{REFERENCES}

Alderfer, C.P. (1977). Group and intergroup relations. In J.R. Hackman \& J.L. Suttle (Eds.), Improving life at work. Santa Monica, CA: Goodyear.

Ancona, D.G., \& Caldwell, D.F. (1988). Beyond task and maintenance: Defining external functions in groups. Groups and Organizations, 13, 468-494.

Bailey, D. (1991). Designing and sustaining effective organizational teams. In R.L. Edwards \& J.A. Yankey (Eds.), Skills for effective human services management (pp. 142-154). Silver Spring, MD: National Association of Social Workers Press.

Barker, I. (1989). Multidisciplinary teamwork. Central Council of Education and Training in Social Work, London. In S. Ramon (Ed.), Psychiatric hospital closure: Myths and realities. London: Chapman \& Hall.

Bond, G.R., Pensec, M., Dietzen, L., McCafferty, D., Giemza, R., \& Sipple, H.W. (1991). Intensive case management for frequent users of psychiatric hospitals in a large city: A comparison of team and individual caseloads. Psychosocial Rehabilitation Joumal, 15, 90-98.

Cassell, E.J. (1977). How does interdisciplinary work get done? In H.T. Engelhardt, Jr. \& D. Callahan (Eds.), Knowledge, value and belief (Vol. 2). Hastings-on-Hudson, NY: The Hastings Center, Institute of Society, Ethnics and the Life Sciences.

Delkeskamp, C. (1977). Interdisciplinarity: A critical appraisal. In H.T. Engelhardt Jr. \& D. Callahan (Eds.), Knowledge, value and belief (Vol. 2). Hastings-on-Hudson, NY: The Hastings Center, Institute of Society, Ethics and the Life Sciences.

Ducanis, A.J., \& Golin, A.K. (1979). The interdisciplinary health care tam: A handbook. Germantown, MD: Aspen Systems Corporation.

Folkins, C., Wieselberg, N., \& Spensley, J. (1981). Discipline stereotyping and evaluative attitudes among community mental health center staff. American Joumal of Orthopsychiatry, 51, 140-148.

Frazier, S.H. (1985). Mental health team practice. In P.J. Lecca \& J. McNeil (Eds.), Interdisciplinary team practice: Issues and trends (pp. 42-56). New York: Praeger.

Goodman, P.S., Ravlin, E.C., \& Argote, L. (1986). Current thinking about groups: Setting the stage for new ideas. In P.S. Goodman \& Associates, Designing effective work groups (pp. 1-33). San Francisco: JosseyBass.

Hackman, J.R. (1987). The design of work teams. In J.W. Lorsch (Ed.), Handbook of organizational behavior (pp. 315-342). Englewood Cliffs, NJ: Prentice-Hall.

Hackman, J.R., \& Oldham, G.R. (1980). Work redesign. Reading, MA: Addison-Wesley Publishing Company.

Hackman, J.R., \& Associates. (1990). Groups that work and those that don't: Creating conditions for effective teamwork. San Francisco: Jossey-Bass.

Janis, I. (1971). Victims of groupthink. Boston: Houghton Mifflin.

Jantsch, E. (1971). Inter- and transdisciplinary university: A systems approach to education and innovation. Ekistics, 32, 430-437. 
Lecca, P.J., \& McNeil, J.S. (Eds.). (1985). Interdisciplinary team practice: Issues and trends. New York: Praeger. Lichtenberg, P.A., Strzepek, D.M., \& Zeiss, A.M. (1990). Bringing psychiatric aides into the treatment team. Gerontology \& Geriatrics Education, 10(4), 63-73.

Lister, L. (1982). Role training for interdisciplinary health teams. Health Eo Social Work, 7, 19-25.

Mitchell, R. (1986). Team building by disclosure of internal frames of reference. Journal of Applied Behavioral Science, 22, 15-28.

Ostrander, E.R. (1974). The visual-semantic communication gap: A model and some implications for collaboration between architects and behavioural scientists. Man-Environment Systems, 4, 47-53.

Ramon, S. (1992). The workers' perspective: Living with ambiguity, ambivalence and challenge. In S. Ramon (Ed.), Psychiatric hospital closure: Myths and realities (pp. 85-121). London: Chapman \& Hall.

Ramon, S. (Ed.). (1992). Psychiatric hospital closure: Myths and realities. London: Chapman \& Hall.

Rendell, R. (1988). Interdisciplinary collaboration, communication patterns and personality characteristics within milieu teams in a children's psychiatric hospital. Doctoral Dissertation, School of Education, The University of Michigan. (University Microfilms No. 88-12972)

Salas, E. (1993). Team training and performance. Psychological Science Agenda (American Psychological Association), 6, 9-11.

Shalinsky, W. (1989). Polydisciplinary groups in the human services. Small Group Behavior, 20, 203-219.

Stahelski, A.J., \& Tsukuda, R.A. (1990). Predictors of cooperation in health care teams. Small Group Research, 21, 220-233.

Sundstrom, E., De Meuse, K. P., \& Futrell, D. (1990). Work teams: Applications and effectiveness. American Psychologist, 45, 120-133.

Toseland, R.W., Palmer-Ganeles, J., \& Chapman, D. (1986). Teamwork in psychiatric settings. Social Work, 31, 46-52.

Vinokur-Kaplan, D., \& Walker-Burt, G. (1994). Meeting professionals' training needs during retrenchment: An example of federal, state and university collaboration with public psychiatric hospitals. Administration and Policy in Mental Health, 21, 525-530.

Vinokur-Kaplan, D. (1993). Treatment teams that work (and those that don't): An application of Hackman's team effectiveness model to psychialric hospitals. Unpublished manuscript (under editorial review). Ann Arbor: School of Social Work, The University of Michigan.

Yank, G.R., Barber, J.W., Hargrove, D.S., \& Whitt, P.D. (1992, August). The mental health treatment team as a work group: Team dynamics and the role of the leader. Psychiatry, 55, 250-264. 